\title{
Ion transfer at polarised liquid-liquid interfaces modified with adsorbed silica nanoparticles
}

\author{
Martha Collins, Marc Hébrant, Grégoire Herzog \\ Laboratoire de Chimie Physique et Microbiologie pour l'Environnement (LCPME), UMR \\ 7564, CNRS - Université de Lorraine, 405 rue de Vandoeuvre, Villers-lès-Nancy, F-54600, \\ France. \\ Email:gregoire.herzog@univ-lorraine.fr; Phone: + 33372747394
}

This document is a postprint. Final version has been published in Electrochimica Acta 2018, 282, 155-162 (https://doi.org/10.1016/i.electacta.2018.06.036).

\begin{abstract}
The interface between two immiscible electrolyte solutions (ITIES) can act as a scaffold for the assembly of nanometer-sized objects. Here we followed the adsorption of silica nanoparticles of $12 \mathrm{~nm}$ diameter at the ITIES by AC voltammetry and their interactions with methylene blue $\left(\mathrm{MB}^{+}\right)$, selected as a model ion, by cyclic voltammetry and UV-vis absorption spectroscopy. We determined the association constant, $K_{a d s}^{a q}$, of adsorption of $\mathrm{MB}^{+}$onto silica nanoparticles to be $1.6610^{5}$, which indicated a strong affinity between them. This strong affinity shifted the Gibbs free energy of transfer by $-8.9 \mathrm{~kJ} \mathrm{~mol}^{-1}$. This is in contrast with the other two ions investigated (Eosin B and tetraethylammonium), which demonstrated low affinity for the silica nanoparticles. By combining the ability of silica to adsorb onto the ITIES and their affinity for $\mathrm{MB}^{+}$, we were able to accumulate $\mathrm{MB}^{+}$at the ITIES.
\end{abstract}




\section{Introduction}

The interface formed between two immiscible electrolyte solutions (ITIES) is a highly reproducible, defect-free surface that allows the assembly of a large variety of nanoscale objects [1-4]. The adsorption of nano-objects at a liquid-liquid interface is governed by their dimensions, the organic-aqueous interfacial tension and the wettability of the material [2,5-8]. The ITIES allows the application of an external electric field that can drive the adsorption of nanoparticles $\left(\mathrm{Au}\right.$ or $\left.\mathrm{TiO}_{2}\right)$ to the interface [9-11]. Carbon nanomaterials (e.g. carbon nanotubes, graphene and graphite flakes) [12-15] and gold nanoparticles [16,17] adsorbed at the ITIES improve electron transfer kinetics between electron donors and acceptors distributed on either sides of the interface [14-17]. The nano-objects assembled at the interface act as conductive rafts floating at the interface catalysing electron transfer through Fermi level equilibration [18,19]. Gold nanoparticles have also been injected onto the interface between a mixture of heptane and 1,2-dichloroethane and water to form a self-assembled monolayer, which exhibits reflectance and electrical conductance, opening the way to the development of electrovariable optical materials [20]. Despite the abundant literature on silica nanoparticles [7,21-25], their assembly at the ITIES has not been investigated yet. Nevertheless, silica sphere structures have been self-assembled at non-polarised liquid-liquid interfaces to fabricate 2 or $3 \mathrm{D}$ ordered structures with potential applications in optical, magnetic and electronic devices as photonic band gap materials [26]. Li et al modified the surfaces of silica spheres and then selfassembled them at the liquid-liquid interface in order to fabricate 2D/3D film structures [26]. The ability to generate low-dimensional nanostructures is by far the most popular application of self-assembled silica nanoparticles at non-polarised liquid-liquid interfaces. The film obtained at the interface after spontaneous adsorption of the silica nanoparticles has low resistance to lateral motion and so is transferrable, allowing it to be used for other applications [27]. The growing interest for the use of silica-based materials at the liquid-liquid interface is also due to their favourable adsorption kinetics and selectivity [28], which could be harnessed to the development of new sensing methods [29,30]. ITIES was modified by the electrogeneration of mesoporous silica deposits [31-35], which were the result of an electrochemically driven ion transfer followed by interfacial precipitation. Mesoporous silica was generated at the ITIES by the transfer of a cationic surfactant (e.g. trimethylhexadecylammonium) from the organic phase to the aqueous phase containing hydrolysed tetra(alkoxy)silanes, catalysing the condensation reactions of the sol-gel process. Micro-ITIES arrays were also modified with mesoporous silica channels prepared ex-situ by a Stöber-like method [36]. The vertically aligned channels obtained have demonstrated their 
potential for analytical applications [37-40]. We investigated here the adsorption of silica nanoparticles onto the ITIES and their impact on the electrochemical transfer behaviour of ions (e.g. methylene blue, eosin B and tetraethylammonium) in the view of developing new analytical methods. Since silica nanoparticles themselves do not have any electrochemical signal at the ITIES they can serve as an aid to enhance the selectivity and preconcentration of target ionic species at the interface and thus their transfer across the ITIES. This ability to detect ionic species is of major benefit in both environmental monitoring and clinical diagnosis. The sensing of synthetic organic molecules, such as drug molecules and pollutants, using silica nanoparticles adsorbed at the ITIES to improve sensitivity is of significant interest.

\section{Experimental section}

\subsection{Chemicals \& Reagents}

The high density organic phase electrolyte was 1,2-dichloroethane (1,2-DCE, $\geq 99 \%$ SigmaAldrich) containing $10 \mathrm{mM}$ Bis (triphenylphosphoranyldiene) ammonium tetrakis (4chlorophenylborate) $\left(\mathrm{BTPPA}^{+} \mathrm{TPBCl}^{-}\right)$. The organic salt was prepared by metathesis of Bis (triphenylphosphoranyldiene) ammonium chloride (BTPPA ${ }^{+} \mathrm{Cl}^{-}, 97 \%$ Aldrich) and Potassium tetrakis (4-chlorophenylborate) $\left(\mathrm{K}^{+} \mathrm{TPBCl}^{-}, \geq 98 \%\right.$ Fluka) [31]. Lithium Chloride ( $\mathrm{LiCl}, \geq 99 \%$ Aldrich) was used as the aqueous phase electrolyte. Solutions of the interfacial active ions: Tetraethylammonium chloride $\left(\mathrm{TEA}^{+} \mathrm{Cl}^{-}, \geq 99 \%\right.$ Fluka), Methylene Blue (> 82\% Fluka) and Eosin B (> 85\% Sigma-Aldrich), were prepared in the aqueous phase electrolyte. The Ludox ${ }^{\circledR}$ HS-40 colloidal silica $\left(\emptyset_{\text {mean }}=12 \mathrm{~nm}, 10.6<\varnothing<13.7 \mathrm{~nm}\right)$ was purchased from Aldrich. Ferric chloride hexahydrate $\left(\mathrm{FeCl}_{3} .6 \mathrm{H}_{2} \mathrm{O}, \geq 99 \%\right.$ Fluka) was used to prepare silver/silver chloride reference electrodes.

\subsection{Experimental methods}

The custom-made electrochemical cell $\left(A_{\text {interface }}=1.13 \mathrm{~cm}^{2}\right)$ consisted of 2 sets of platinum mesh and silver/silver chloride wires as counter and reference electrodes respectively for both aqueous and organic phases. Different electrochemical cells were used and their compositions were as follows:

Electrochemical cell 1: 


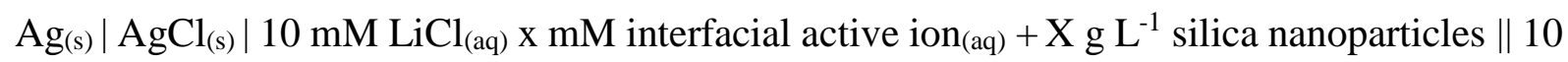
$\mathrm{mM} \mathrm{BTPPA}^{+} \mathrm{TPBCl}^{-}{ }_{(\text {org }}$ ) in 1,2-DCE | Saturated $\mathrm{BTPPA}^{+} \mathrm{Cl}^{-}$in $10 \mathrm{mM} \mathrm{LiCl}$ in $\mathrm{H}_{2} \mathrm{O}\left|\mathrm{AgCl}_{(\mathrm{s})}\right|$ $\mathrm{Ag}_{(\mathrm{s})}$;

Electrochemical cell 2:

$\mathrm{Ag}_{(\mathrm{s})}\left|\mathrm{AgCl}_{(\mathrm{s})}\right| 100 \mathrm{mM} \mathrm{LiCl}_{(\mathrm{aq})}+\mathrm{X} \mathrm{g} \mathrm{L}{ }^{-1}$ silica nanoparticles $\| 10 \mathrm{mM} \mathrm{BTPPA}^{+} \mathrm{TPBCl}^{-}{ }_{(\text {org }}$ ) in 1,2-DCE $\mid$ Saturated $\mathrm{BTPPA}^{+} \mathrm{Cl}^{-}$in $10 \mathrm{mM} \mathrm{LiCl}$ in $\mathrm{H}_{2} \mathrm{O}\left|\mathrm{AgCl}_{(\mathrm{s})}\right| \mathrm{Ag}_{(\mathrm{s})}$;

Electrochemical cell 3:

$\mathrm{Ag}_{(\mathrm{s})}\left|\mathrm{AgCl}_{(\mathrm{s})}\right| 10 \mathrm{mM} \mathrm{HCl}_{(\mathrm{aq})}+\mathrm{Xg} \mathrm{\textrm {L } ^ { - 1 }}$ silica nanoparticles $\| 10 \mathrm{mM} \mathrm{BTPPA}^{+} \mathrm{TPBCl}_{(\text {org }}$ ) in 1,2-DCE $\mid$ Saturated $\mathrm{BTPPA}^{+} \mathrm{Cl}^{-}$in $10 \mathrm{mM} \mathrm{LiCl}$ in $\mathrm{H}_{2} \mathrm{O}\left|\mathrm{AgCl}_{(\mathrm{s})}\right| \mathrm{Ag}_{(\mathrm{s})}$;

Electrochemical cell 4:

$\mathrm{Ag}_{(\mathrm{s})}\left|\mathrm{AgCl}_{(\mathrm{s})}\right|$ Saturated $\mathrm{BTPPA}^{+} \mathrm{Cl}^{-}$in $10 \mathrm{mM} \mathrm{LiCl}$ in $\mathrm{H}_{2} \mathrm{O} \mid 10 \mathrm{mM} \mathrm{BTPPA}^{+} \mathrm{TPBCl}^{-}$(org) in 40:60 1,2-DCE:5-nonanone (v/v) $\| 10 \mathrm{mM} \mathrm{LiCl}_{(\mathrm{aq})}$ x mM interfacial active ion $(\mathrm{aq})+\mathrm{X} \mathrm{g} \mathrm{L}^{-1}$ silica nanoparticles $\left|\mathrm{AgCl}_{(\mathrm{s})}\right| \mathrm{Ag}_{(\mathrm{s})}$.

Two electrochemical techniques were used during these experiments - Alternating Current (AC) Voltammetry and Cyclic Voltammetry (CV). Cyclic voltammetry experiments were run with an Autolab 302N potentiostat using Nova 1.10.1.9 software by Metrohm Autolab B.V. The formal transfer potential of $\mathrm{TEA}^{+}, \Delta_{o}^{w} \phi_{T E A^{+}}^{0^{\prime}}=0.049 \mathrm{~V}$ [41], was used to calibrate the potential window. $\mathrm{TEA}^{+}$was added to the aqueous phase of the electrochemical cell at the end of a series of experiments for potential calibration purposes. For $\mathrm{CV}$ experiments, the transfers of $\mathrm{Li}^{+}$and $\mathrm{Cl}^{-}$from the aqueous phase to the DCE phase establish the positive and negative limits of the potential window, respectively. In the presence of $\mathrm{SiO}_{2}$, the potential was calibrated using the limits of the potential window as previous studies have shown that the transfer of both $\mathrm{Li}^{+}$and $\mathrm{Cl}^{-}$is not hindered by the presence of electrogenerated silica [33]. Scans were run at a scan rate of $5 \mathrm{mVs}^{-1}$. AC voltammetry experiments were run using GPES software with an Autolab PGSTAT-12. Parameters for the AC experiments were as follows - modulation time: $0.33 \mathrm{~s}$, interval time: $0.73 \mathrm{~s}$, frequency: $6 \mathrm{~Hz}$, step potential: $5 \mathrm{mV}$, amplitude: $5 \mathrm{mV}$ RMS. The potential region was scanned at phase angles of $0^{\circ}$ and $90^{\circ}$. In this frequency range, the impedance response of the cell is determined by a single RC component associated with the uncompensated resistance and the double-layer capacitance $[10,42]$.

UV/Vis absorption spectroscopy experiments were carried out using an Agilent Technologies Cary $60 \mathrm{UV}-\mathrm{Vis}$ spectrometer. Solutions analysed were prepared in $10 \mathrm{mM} \mathrm{LiCl}$ and poured in standard plastic cuvettes with a path length of $1 \mathrm{~cm}$. For the determination of the association constant and the total number of adsorption sites by UV-vis absorption spectroscopy, Solutions 
of $50 \mu \mathrm{M}$ of $\mathrm{MB}^{+}$in $10 \mathrm{mM} \mathrm{LiCl}$ with varying concentrations of $\mathrm{SiO}_{2}$ nanoparticles (final silica nanoparticle concentrations were between 0.040 and $0.867 \mathrm{~g} \mathrm{~L}^{-1}$, total volume was $10 \mathrm{~mL}$ ) were poured in a stirred ultrafiltration cell $(25 \mathrm{~mm}$ diameter, Amicon Model 8010, Millipore, Carrigtwohill, Ireland) equipped with a regenerated cellulose membrane (PLGC, $10 \mathrm{kDa}$, Millipore). The filtrate was collected and analysed by UV-vis absorption spectroscopy. Preconcentration experiments were prepared with $200 \mathrm{~mL}$ of a $25 \mu \mathrm{M} \mathrm{MB}^{+}$solution containing $0.05 \mathrm{~g} \mathrm{~L}^{-1}$ of $\mathrm{SiO}_{2}$ nanoparticles. The solutions were mixed for $5 \mathrm{~min}$ and then centrifuged at $10,000 \mathrm{rpm}$ for $15 \mathrm{~min}$. The supernatant was removed and $3 \mathrm{~mL}$ of a $10 \mathrm{mM} \mathrm{LiCl}$ solution was added to the nanoparticle- $\mathrm{MB}^{+}$precipitate, which is then used as the aqueous phase in the electrochemical cell.

\section{Results and discussion}

\subsection{Silica nanoparticles adsorption at the ITIES}

Previous studies on the behaviour of nanoparticles at the liquid-liquid interface have shown that their adsorption is the result of the presence of a promoter or a modifier that weakens the electrostatic repulsion between the nanoparticles in suspension and allows the assembly of nanoparticles at the interface [43]. An alternative to this chemically induced assembly is the application of an interfacial potential difference that causes the assembly [9]. The adsorption of silica nanoparticles was investigated here by both cyclic and AC voltammetries at the ITIES (Figure 1). After the addition of $0.5 \mathrm{~g} \mathrm{~L}^{-1}$ silica nanoparticles to the aqueous phase, there was no significant changes to the $\mathrm{CV}$, suggesting that no ion transfer is taking place in the potential window due the presence of the silica nanoparticles. 

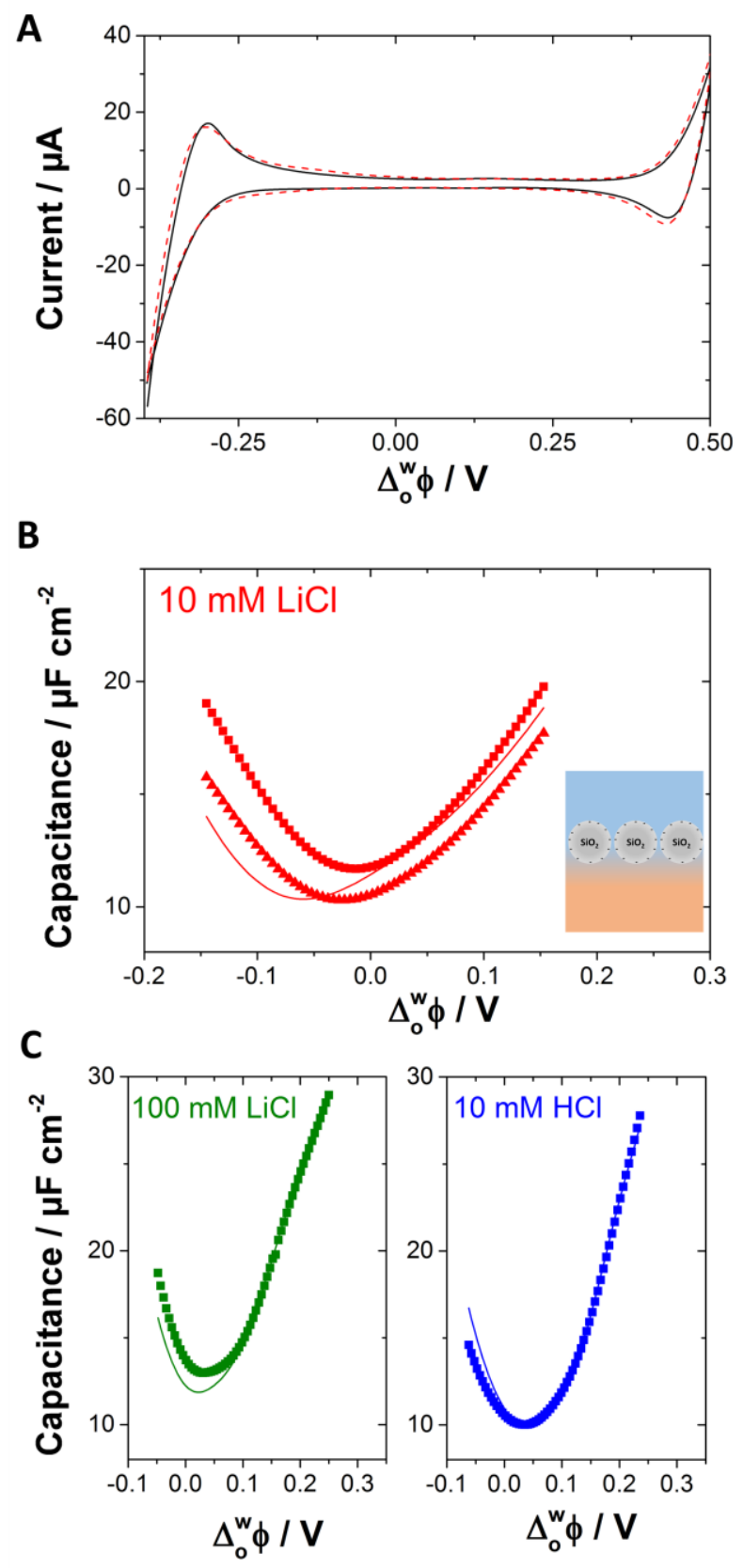

Figure 1: (A) Cyclic voltammetry in the absence (black solid line) and in the presence (red dashed line) of $0.5 \mathrm{~g} \mathrm{~L}^{-1}$ of silica nanoparticles in the aqueous phase. Electrochemical cell $1, v$ $=5 \mathrm{mV} \mathrm{s}^{-1}$; (B) Potential dependence of the interfacial capacitance for the blank cell (red solid line) and for ( $\mathbf{\Delta}) 0.05$ and $(\boldsymbol{\square}) 0.1 \mathrm{~g} \mathrm{~L}^{-1}$ of silica nanoparticles. Electrochemical cell 1. (C) Potential dependence of the interfacial capacitance for the blank cell (solid line) and for ( $\mathbf{\square})$ $0.1 \mathrm{~g} \mathrm{~L}^{-1}$ of silica nanoparticles with $100 \mathrm{mM} \mathrm{LiCl}$ (Electrochemical cell 2) or $10 \mathrm{mM} \mathrm{HCl}$ (Electrochemical cell 3) as an aqueous electrolyte solution. 
Silica nanoparticles did not transfer across the interface and remained on the aqueous side of the interface throughout the potential window. AC voltammetry is more sensitive to interfacial phenomena than cyclic voltammetry and was then further used for the characterisation of the interface modified with silica nanoparticles. Even with quantities of silica nanoparticles as low as $0.05 \mathrm{~g} \mathrm{~L}^{-1}$, significant changes were visible on the $\mathrm{AC}$ voltammograms recorded in the potential region where no background salt ion transfer was observed in cyclic voltammetry (Figure 1B). The differential capacitance was calculated from the AC voltammograms (see Experimental section). The potential of zero charge was taken as the potential of minimum of capacitance. In the absence of silica nanoparticles, it was measured at $-0.06 \mathrm{~V}$. Upon addition of silica nanoparticles to the aqueous phase, the capacitance value at $-0.145 \mathrm{~V}$ increased from $14\left(0 \mathrm{~g} \mathrm{~L}^{-1}\right)$ to $19 \mu \mathrm{F} \mathrm{cm}^{-2}\left(0.1 \mathrm{~g} \mathrm{~L}^{-1}\right)$ indicating that the quantity of charge located at the interface grew in the presence of silica nanoparticles. This behaviour can be attributed to the adsorption of negatively charged silica nanoparticles accumulating at the ITIES. This result is in agreement with that previously obtained for the interfacial assembly of $\mathrm{TiO}_{2}$ nanoparticles [10] or $\mathrm{Au}$ nanoparticles [9] upon polarization at the liquid-liquid interface. Positively charged $\mathrm{TiO}_{2}$ particles (at $\mathrm{pH} 3.5$ ) caused the capacitive current to increase at positive Galvani potentials, whereas at $\mathrm{pH} 11, \mathrm{TiO}_{2}$ nanoparticles are negatively charged due to ionisation of the oxide surface and so the interfacial excess of the particles is increased at negative potentials. The potential value for the minimum capacitance shifted to higher potential values with the increase of silica nanoparticles amount in suspension (from $-0.062 \mathrm{~V}$ in the absence of silica nanoparticles to $-0.013 \mathrm{~V}$ for $0.1 \mathrm{~g} \mathrm{~L}^{-1}$ ). This observation agrees with previous studies on the behaviour of haemoglobin at the liquid-liquid interface where positively charged haemoglobin caused a shift to lower potential values [42]. At a higher ionic strength, $I$, of the aqueous phase $(I=100 \mathrm{mM})$, the potential for the lowest capacitance value was slightly shifted from +0.020 to $+0.035 \mathrm{~V}$ when the concentration of silica nanoparticles increased from 0 to $0.1 \mathrm{~g} \mathrm{~L}^{-1}$ (Figure 1C). The capacitance variation was very limited due to the charge screening of higher electrolyte concentration. When the $\mathrm{pH}$ was decreased to $2(10 \mathrm{mM} \mathrm{HCl})$ no significant potential shift or increase in capacitance values was observed (Figure 1C). At this $\mathrm{pH}$, silica nanoparticles are expected to be nearly neutral [44] explaining why changes in the potential of zero charge or in the capacitance were not observed. In the previous experiments, the electrochemical cell was prepared with an organic phase denser than water (the organic solvent was 1,2 -dichloroethane, $d=1.25 \mathrm{~g} \mathrm{~mL}^{-1}$ ). To prove that silica nanoparticles assembled at the liquid-liquid interface, and did not just sediment because of gravity, an organic phase less dense than water was used (Figure 2). Recent studies have shown that a mixture of 5-nonanone and 
1,2-dichloroethane is lighter than water and it can be used for electrochemistry at the ITIES [45]. We recorded AC voltammetry at such an electrochemical cell in the absence and in the presence of $0.5 \mathrm{~g} \mathrm{~L}^{-1}$ silica nanoparticles in the aqueous phase. The potential of zero charge shifted to higher potential values and the capacitance increased at $-0.195 \mathrm{~V}$ from 26 to $32 \mu \mathrm{F}$ $\mathrm{cm}^{-2}$ in the presence of silica nanoparticles. This observation confirmed that silica nanoparticles adsorbed at the ITIES.

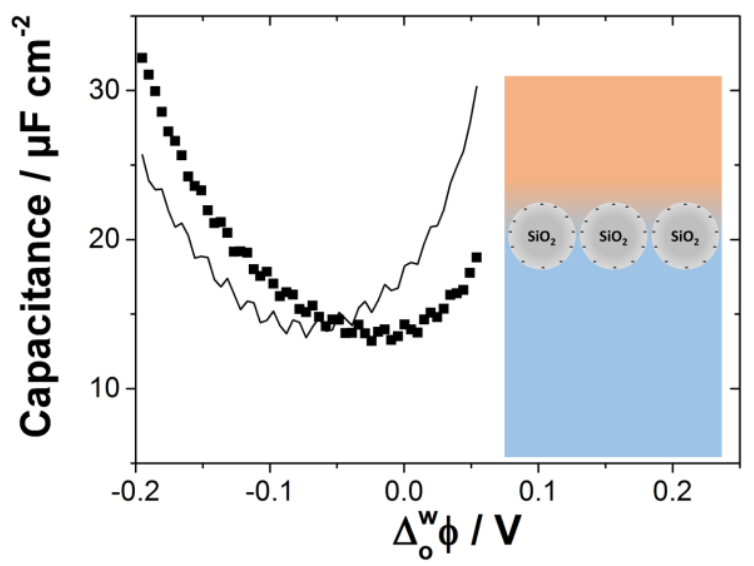

Figure 2: Potential dependence of the interfacial capacitance for the blank cell (solid line) and for $(\boldsymbol{\square}) 0.5 \mathrm{~g} \mathrm{~L}^{-1}$ of silica nanoparticles with a denser aqueous phase. Electrochemical cell 4.

\subsection{Silica nanoparticles interactions studies in aqueous solutions}

Interactions between the negatively charged silica nanoparticles and charged organic dyes (cationic methylene blue, $\mathrm{MB}^{+}$; anionic Eosin B, EB') were studied in a monophasic aqueous system. The organic dye was dissolved in the aqueous phase at $50 \mu \mathrm{M}$ and a UV-vis absorption spectrum was recorded before and after a silica nanoparticle suspension was added to reach a concentration of $0.5 \mathrm{~g} \mathrm{~L}^{-1}$. In the absence of silica nanoparticles, two bands were observed in the UV-vis. spectrum of $\mathrm{MB}^{+}$(Figure 3). The main band at $\lambda=664 \mathrm{~nm}$ is attributed to the $\mathrm{n}-\pi^{*}$ transition whereas the shoulder at $\lambda=614 \mathrm{~nm}$ is attributed to the vibronic transition [46-48]. In the presence of silica nanoparticles, the UV-vis. spectrum looks quite different with the largest band at $\lambda=590 \mathrm{~nm}$ and a smaller at $\lambda=664 \mathrm{~nm}$, suggesting that $\mathrm{MB}^{+}$and silica nanoparticles interact with one another. This blue shift is attributed to the aggregation of $\mathrm{MB}^{+}$to form dimers, trimers...[49] on the silica nanoparticles surface and is in good agreement with spectra reported in the literature for $\mathrm{MB}^{+}$adsorbed onto silica-coated magnetic nanoparticles [50]. There was no difference between the $\mathrm{EB}^{-}$spectra in the absence or in the presence of silica nanoparticles, 
showing that there was no interaction between both negatively charged species (data not shown).

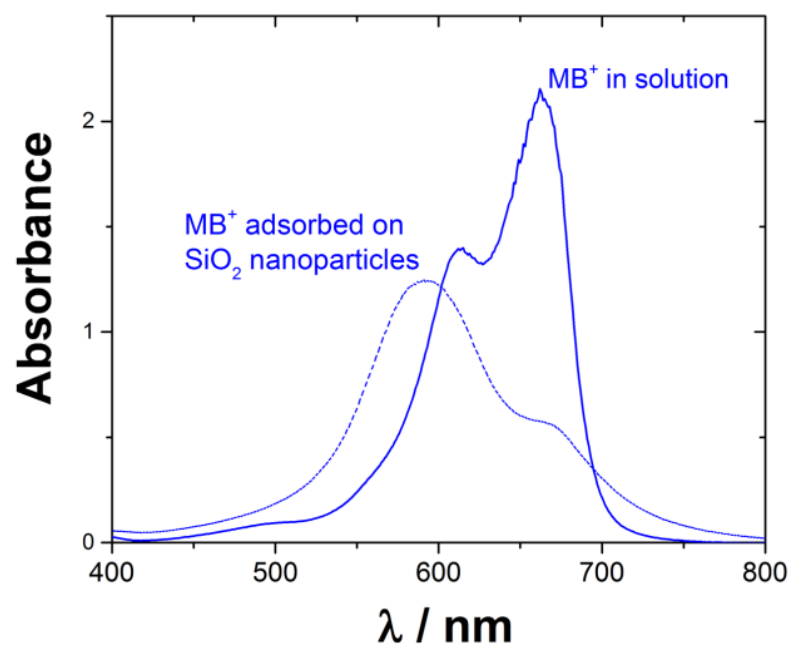

Figure 3: UV/Vis absorption spectroscopy of $50 \mu \mathrm{M} \mathrm{MB}^{+}$free in solution (solid line) and adsorbed on $0.5 \mathrm{~g} \mathrm{~L}^{-1}$ of silica nanoparticles (dashed line). Both solutions contained $10 \mathrm{mM}$ LiCl.

We aimed at determining the total number of sites, $S_{T}$, available for $\mathrm{MB}^{+}$adsorption on silica nanoparticles and the association constant, $K_{a d s}^{a q}$, of adsorption of $\mathrm{MB}^{+}$onto silica nanoparticles. The adsorption of free $\mathrm{MB}^{+}$in solution onto silica free sites, $S_{F}$, can be described by the following equilibrium.

$$
\begin{gathered}
M B_{\text {free }}^{+}+S_{F}=M B_{a d s}^{+} \\
K_{a d s}^{a q}=\frac{\left[M B^{+}\right]_{a d s}}{\left[M B^{+}\right]_{\text {free }}\left[S_{F}\right]}
\end{gathered}
$$

The total number of sites is equal to the sum of the occupied sites, $S_{O}$, and of the free sites, $S_{F}$. Similarly, the total number of $\mathrm{MB}^{+}$is equal to the sum of adsorbed $\mathrm{MB}^{+}$and of $\mathrm{MB}^{+}$free in solution. Since we worked at constant volume, equations 3 and 4 are valid.

$$
\begin{gathered}
{\left[S_{T}\right]=\left[S_{O}\right]+\left[S_{F}\right]} \\
{\left[M B^{+}\right]_{T}=\left[M B^{+}\right]_{\text {ads }}+\left[M B^{+}\right]_{\text {free }}}
\end{gathered}
$$

We assume that the number of occupied sites is equal to the number of $\mathrm{MB}^{+}$molecules adsorbed, equation (2) becomes:

$$
K_{a d s}^{a q}=\frac{\left[M B^{+}\right]_{a d s}}{\left(\left[M B^{+}\right]_{T}-\left[M B^{+}\right]_{a d s}\right)\left(\left[S_{T}\right]-\left[M B^{+}\right]_{a d s}\right)}
$$

Experimentally, we investigated the adsorption of $\mathrm{MB}^{+}$onto silica by $\mathrm{UV}$-vis spectroscopy adsorption. We maintained the initial amount in solution of $\mathrm{MB}^{+}$constant, $\left[\mathrm{MB}^{+}\right]_{T}=50 \mu \mathrm{M}$, 
throughout the series of experiments and we varied the silica concentration from 0.040 to 0.867 $\mathrm{g} \mathrm{L}^{-1}$. Silica nanoparticles and $\mathrm{MB}^{+}$were mixed together and the solution was then filtered through a membrane. The filtrate was collected and analysed by UV/Vis absorption spectroscopy, which allowed the determination of the amount of $\mathrm{MB}^{+}$present in the filtrate, $\left[\mathrm{MB}^{+}\right]_{\text {free }}$ deduced from the optical density variation at $650 \mathrm{~nm} .\left[\mathrm{MB}^{+}\right]_{\text {ads }}$ were then deduced from equation (4) and the results were plotted as the function of silica concentration and fitted with a Langmuir isotherm to determine (a) the $\mathrm{SiO}_{2}$ surface area per $\mathrm{MB}^{+}$(i.e. equivalent to the total site concentration) and (b) the adsorption constant $\left(K_{a d s}^{a q}\right)$. These two parameters were left as adjustable parameters [51]. The best fit was obtained for $K_{a d s}^{a q}=1.6610^{5}$ and a $=1 \mathrm{~nm}^{2} /$ $\mathrm{MB}^{+}$. This represents approximately 900 adsorption sites per nanoparticle. $K_{a d s}^{a q}$ can be related to the free Gibbs energy of adsorption:

$$
\Delta G_{\mathrm{SiO}_{2}-M B^{+}}^{0}=-R T \ln K_{a d s}^{a q}
$$

Where $T$ is the temperature $(T=293 \mathrm{~K})$ and $R$ is the universal gas constant $\left(R=8.314 \mathrm{~J} \mathrm{~mol}^{-1}\right.$ $\mathrm{K}^{-1}$ ). The value of $-29.3 \mathrm{~kJ} \mathrm{~mol}^{-1}$ for the free Gibbs energy of adsorption testified of the spontaneous nature of the adsorption of $\mathrm{MB}^{+}$onto silica nanoparticles. These results are in agreement with the existing literature, where spontaneous adsorption of $\mathrm{MB}^{+}$on mesoporous silica formed as a thin film on an electrode was reported [52] with similar free Gibbs energy of adsorption. Based on the fitting of Figure 4, the surface area per $\mathrm{MB}^{+}$was calculated at $1 \mathrm{~nm}^{2}$, which is lower than the results of the adsorption of one $\mathrm{MB}^{+}$molecule for every $3 \mathrm{~nm}^{2}$ of silica reported in the literature for a different type of silica and experimental conditions [9].

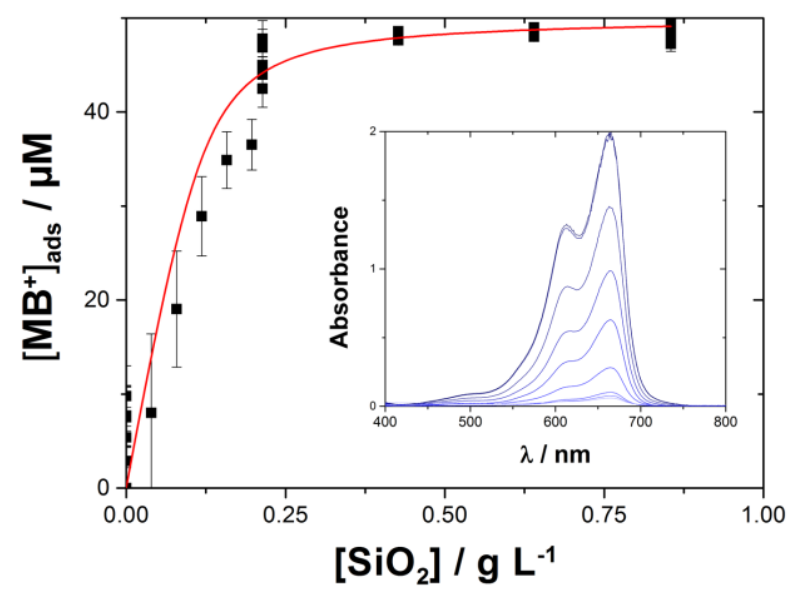

Figure 4: Amount of adsorbed $\mathrm{MB}^{+}$as a function of the amount of silica nanoparticles. Experimental data represented by the black squares were fitted using a Langmuir isotherm. Inset shows the UV-vis absorption spectra of free $\mathrm{MB}^{+}$in the filtrate after mixing with concentrations of silica nanoparticles (between 0.040 and $0.867 \mathrm{~g} \mathrm{~L}^{-1}$ ) and filtration. 


\subsection{Ion transfer at the ITIES modified with silica nanoparticles}

As mentioned in the previous section, UV-vis absorption spectroscopy experiments showed a strong affinity between the $\mathrm{MB}^{+}$and silica nanoparticles in an aqueous solution. Cyclic voltammetry was used to study the effect of the interaction between silica nanoparticles and ions on the ion transfer at the ITIES. In the absence of silica nanoparticles, the standard transfer potential of $\mathrm{MB}^{+}$was measured at $\Delta_{o}^{w} \phi_{M B^{+}}^{0^{\prime}}=-0.223 \mathrm{~V}$ (Figure 5), which was only $0.034 \mathrm{~V}$ larger than the open circuit potential of electrochemical cell $1\left(\Delta_{o}^{w} \phi_{o c p}=-0.257 \mathrm{~V}\right)$. The concentration ratio of $\mathrm{MB}^{+}$in both phases at open circuit potential can be calculated using the Nernst equation:

$$
\frac{\left[M B^{+}\right]_{o r g}}{\left[M B^{+}\right]_{a q}}=e^{\left(\Delta_{o}^{w} \phi_{o c p}-\Delta_{o}^{W} \phi_{M B^{+}}^{0^{\prime}}\right) \frac{z F}{R T}}
$$

$\Delta_{o}^{w} \phi_{M B^{+}}^{0^{\prime}}$ is the formal transfer potential of $\mathrm{MB}^{+}, z$ is the $\mathrm{MB}^{+}$charge and $F$ is the Faraday constant. At open circuit potential, the ratio $\frac{\left[M B^{+}\right]_{o r g}}{\left[M B^{+}\right]_{a q}}$ was 0.26 in the absence of silica nanoparticles at the interface, confirming the spontaneous $\mathrm{MB}^{+}$transfer from the aqueous to the organic phase. The spontaneous transfer was observed experimentally at open circuit potential with a blue coloration of the organic solution. However, in the presence of silica nanoparticles, the transfer potential of $\mathrm{MB}^{+}, \Delta_{o}^{w} \phi_{M B^{+}}^{1 / 2}$, shifts to a potential of $-0.131 \mathrm{~V}$, confirming the strong affinity between silica nanoparticles and $\mathrm{MB}^{+} . \Delta_{o}^{w} \phi_{M B^{+}}^{1 / 2}$ is calculated as the half-wave potential of $\mathrm{MB}+$ transfer in the presence of silica nanoparticles adsorbed at the ITIES. At open circuit potential and in the presence of silica nanoparticles, the ratio $\frac{\left[\mathrm{MB} \mathrm{B}_{\text {org }}\right.}{\left[\mathrm{MB}^{+}\right]_{a q}}$, calculated with Eq (7), was 0.007 . Less than $1 \%$ of $\mathrm{MB}^{+}$transfers spontaneously across the interface modified with silica nanoparticles. The shift of transfer potential allows the estimation of the Gibbs free energy of ion association between the $\mathrm{MB}^{+}$and the silica nanoparticle adsorbed at the ITIES [53-55].

$$
\Delta G_{S^{0} O_{2}-M B^{+}}^{0, i n t e r f a c e}=z F\left(\Delta_{o}^{w} \phi_{M B^{+}}^{0^{\prime}}-\Delta_{o}^{w} \phi_{M B^{+}}^{1 / 2}\right)
$$

$\Delta G_{\mathrm{SiO}_{2}-\mathrm{MB}^{+}}^{0, \text { interface }}$ was $-8.9 \mathrm{~kJ} \mathrm{~mol}^{-1}$, which is lower than the Gibbs free energy of adsorption, $\Delta G_{\mathrm{SiO}_{2}-\mathrm{MB}^{+}}^{0}$, previously determined in the aqueous phase by UV-vis spectroscopy (Figure 4). The difference between the two energies can be explained by the amphiphilic nature of $\mathrm{MB}^{+}$ 
[56]. Indeed, the presence of the organic solvent at the interface lowers the adsorption constant of $\mathrm{MB}^{+}$onto silica nanoparticles.

A

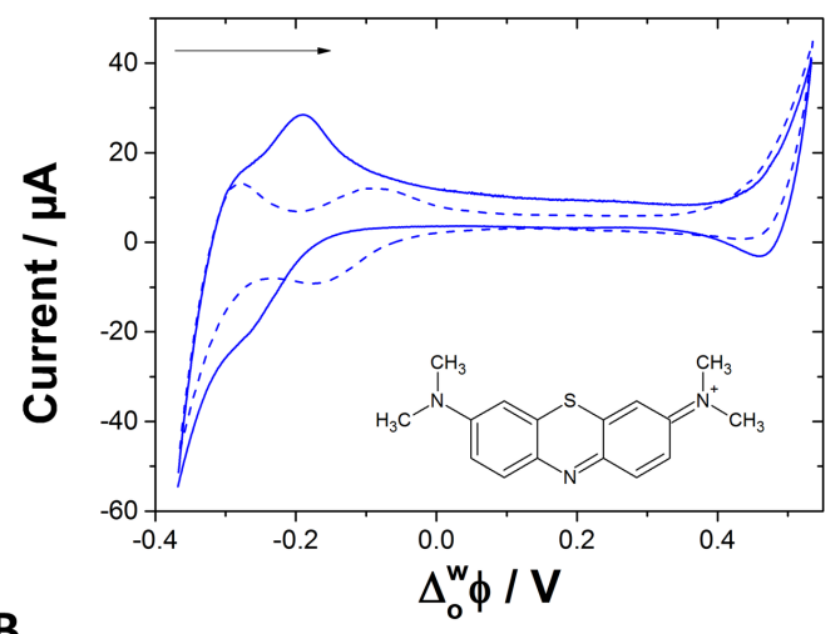

B
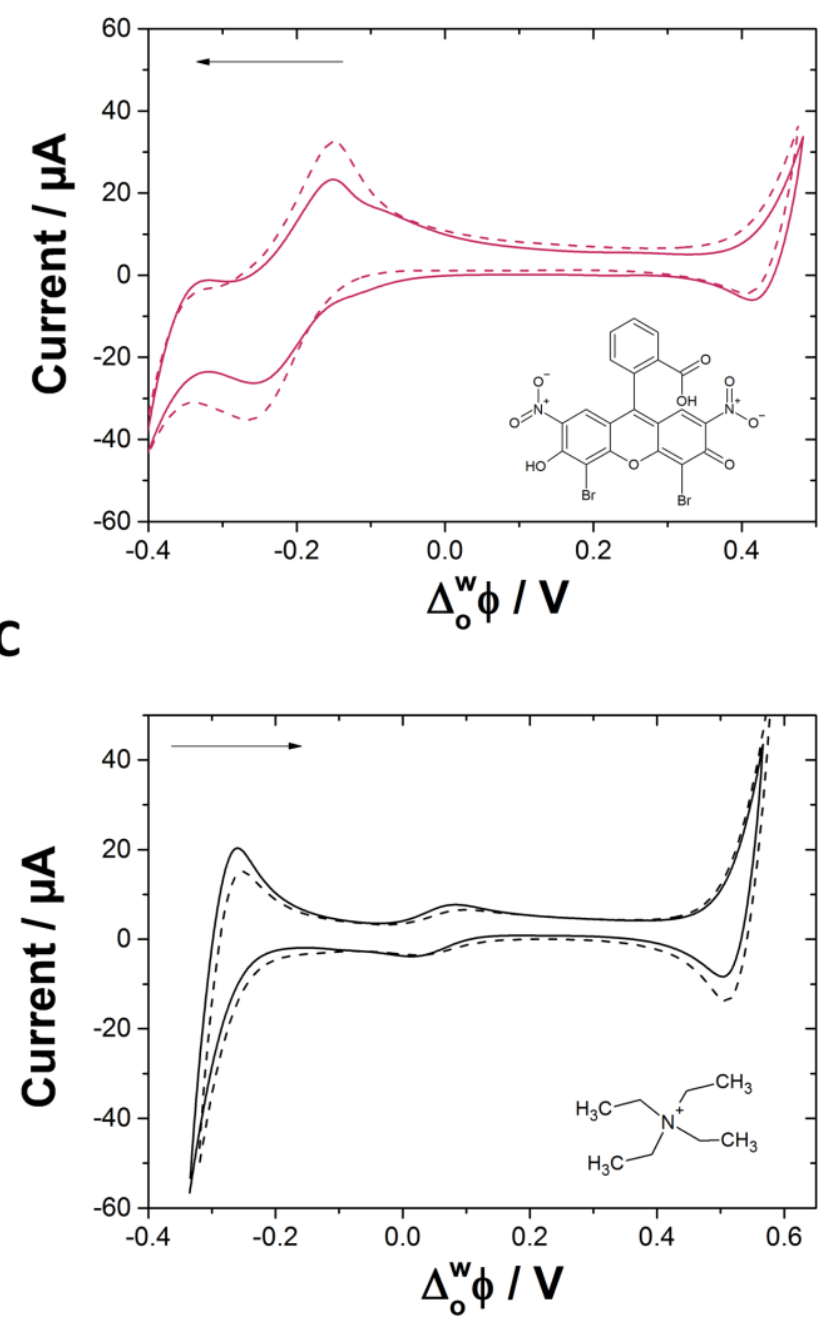

Figure 5: Cyclic voltammetry of (A) $600 \mu \mathrm{M}$ of $\mathrm{MB}^{+}$, (B) $300 \mu \mathrm{M}$ of $\mathrm{EB}^{-}$and (C) $100 \mu \mathrm{M}$ of $\mathrm{TEA}^{+}$in the absence (solid line) and in the presence (dashed line) of (A,B) $0.867 \mathrm{~g} \mathrm{~L}^{-1}$ and (C) 
$1 \mathrm{~g} \mathrm{~L}^{-1}$ of silica nanoparticles in the aqueous phase. Electrochemical cell $1 . v=5 \mathrm{mV} \mathrm{s}^{-1}$. Arrows indicate the initial scan direction.

We also investigated the influence of the presence of silica nanoparticles on anionic $\mathrm{EB}^{-}$and cationic TEA ${ }^{+}$. The transfer potential of both $\mathrm{EB}^{-}(+0.011 \mathrm{~V})$ and $\mathrm{TEA}^{+}(+0.017 \mathrm{~V})$ increased slightly after addition to the silica nanoparticles to the aqueous phase, suggesting that the transfer for these two ions is hindered by the presence of the nanoparticles. Thermodynamic values determined from the cyclic voltammograms for the three different ions are summarised in Table 1.

Table 1: Thermodynamics parameters determined experimentally

\begin{tabular}{|c|c|c|c|c|}
\hline Ion & $\Delta_{o}^{w} \phi_{\text {ion }}^{0^{\prime}} / \mathrm{V}$ & $\Delta G_{i o n}^{0} / \mathrm{kJ} \mathrm{mol}^{-1}$ & $\Delta_{o}^{w} \phi_{i o n}^{1 / 2} / \mathrm{V}$ & $\Delta G_{\text {SiO }_{2}-\text { ion }}^{0, \text { intere }} / \mathrm{kJ} \mathrm{mol}^{-1}$ \\
\hline $\mathbf{M B}^{+}$ & -0.223 & -20.9 & -0.131 & -8.9 \\
\hline $\mathbf{E B}^{-}$ & -0.204 & -19.7 & -0.193 & -1.1 \\
\hline TEA $^{+}$ & +0.049 & +4.7 & +0.066 & -1.6 \\
\hline
\end{tabular}

The interfacial mechanism of $\mathrm{MB}^{+}$transfer in the presence of silica nanoparticles is summarised in Figure $6 . \mathrm{MB}^{+}$have shown a strong affinity constant, $K_{a d s}^{a q}$, for the silica nanoparticles. When silica nanoparticles are adsorbed on the interface, $\mathrm{MB}^{+}$transfer remained possible, provided that a sufficient excess of energy is provided: $\Delta G_{\mathrm{SiO}_{2}-\mathrm{MB}^{+}}^{0, \text { interface }}$. Based on this mechanism, we can harness the affinity between $\mathrm{MB}^{+}$and silica nanoparticles and the adsorption of silica nanoparticles at the ITIES to accumulate $\mathrm{MB}^{+}$ions at the ITIES and increase locally the $\mathrm{MB}^{+}$ concentration.

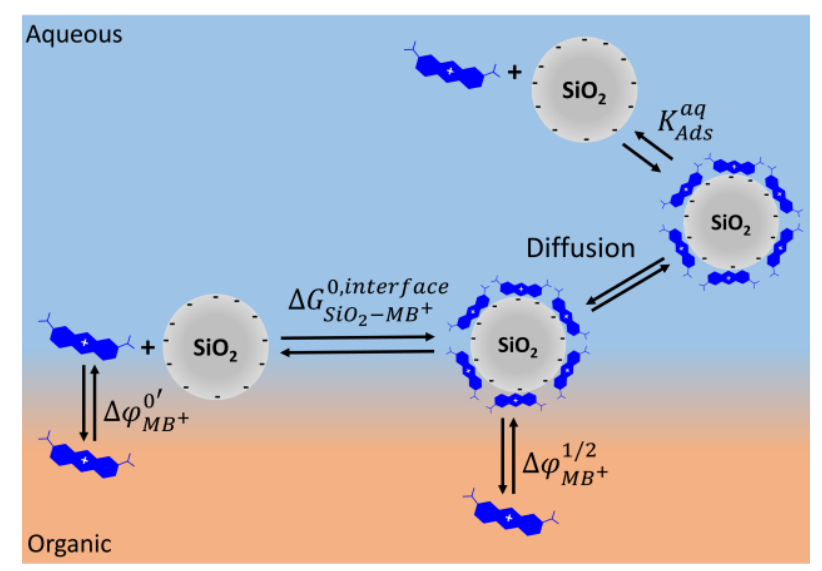


Figure 6: Schematic of the interfacial mechanism for the transfer of $\mathrm{MB}^{+}$in the presence of silica nanoparticles.

To demonstrate the accumulation of $\mathrm{MB}^{+}$at ITIES modified with silica nanoparticles, a solution of $25 \mu \mathrm{M} \mathrm{MB}^{+}$was mixed with $0.05 \mathrm{~g} \mathrm{~L}^{-1}$ of silica nanoparticles. The solution was centrifuged and the supernatant removed. The nanoparticles were then re-suspended in a $10 \mathrm{mM} \mathrm{LiCl}$ solution, which was used to prepare an electrochemical cell. Cyclic voltammograms obtained with such an electrochemical cell showed $\mathrm{MB}^{+}$transfer, whereas no transfer was observed for a $25 \mu \mathrm{M} \mathrm{MB}^{+}$solution in the absence of silica nanoparticles (Figure 7). Such an experiment demonstrated that $\mathrm{MB}^{+}$ions were accumulated at the ITIES with the help of the silica nanoparticles.

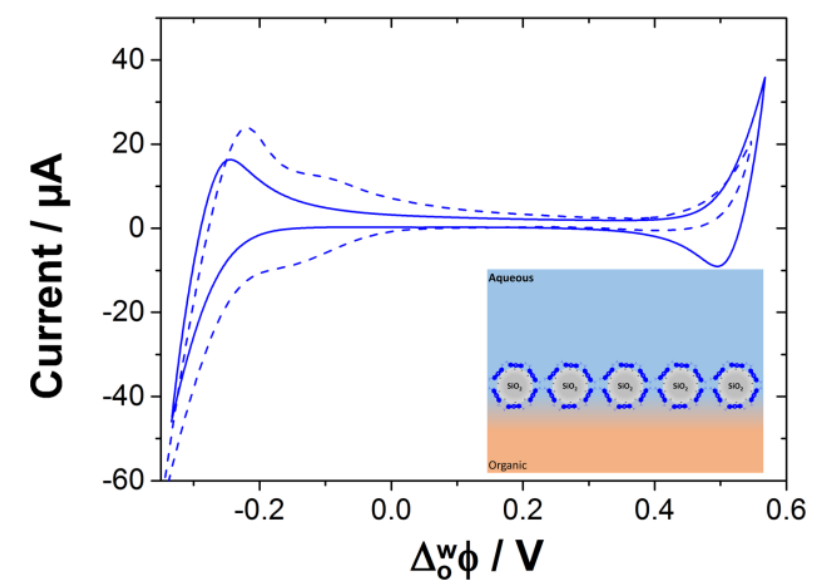

Figure 7: Cyclic voltammetry of $25 \mu \mathrm{M}$ of $\mathrm{MB}^{+}$in the absence of silica nanoparticles (solid line) and in the presence of silica nanoparticles and $\mathrm{MB}^{+}$after centrifugation and re-suspension with $3 \mathrm{~mL}$ of $10 \mathrm{mM} \mathrm{LiCl}$. Initial concentrations were $25 \mu \mathrm{M} \mathrm{MB}^{+}$and $0.05 \mathrm{~g} \mathrm{~L}^{-1}$ of silica nanoparticles. Electrochemical cell 1. $v=5 \mathrm{mV} \mathrm{s}^{-1}$.

\section{Conclusions}

UV-vis absorption spectroscopy and electrochemistry experiments have contributed to the determination of the mechanism of $\mathrm{MB}^{+}$ion transfer at the ITIES modified with silica nanoparticles. AC voltammetry experiments have shown that, upon addition of silica nanoparticles to the aqueous phase, the capacitance value increased, indicating that the quantity of charge located at the interface grew in the presence of silica nanoparticles. This behaviour can be attributed to the adsorption of negatively charged silica nanoparticles accumulating at the ITIES. 
Interactions between the negatively charged silica nanoparticles and charged organic dyes (cationic methylene blue, $\mathrm{MB}^{+}$; anionic Eosin $\mathrm{B}, \mathrm{EB}^{-}$) were studied in a monophasic aqueous system. A change in the shape of the UV-vis spectrum for $\mathrm{MB}^{+}$in the presence of silica nanoparticles suggested that $\mathrm{MB}^{+}$and silica nanoparticles interact with one another. The variation of $\left[\mathrm{MB}^{+}\right]_{a d s}$ was plotted as the function of silica concentration. Experimental results were fitted with a Langmuir isotherm to determine the $\mathrm{SiO}_{2}$ surface area per $\mathrm{MB}^{+}$(i.e. equivalent to the total site concentration) to be $1 \mathrm{~nm}^{2} / \mathrm{MB}^{+}$and the adsorption constant $\left(K_{a d s}^{a q}\right)$ equal to $1.6610^{5}$, indicating a high affinity of $\mathrm{MB}^{+}$for the silica nanoparticle surface. The strong affinity for cationic $\mathrm{MB}^{+}$on the negatively charged silica nanoparticles was also confirmed by cyclic voltammetry, which monitored the transfer potential of the ions at the ITIES. In the presence of silica nanoparticles the transfer potential of $\mathrm{MB}^{+}$shifts to higher potential. The strong affinity of $\mathrm{MB}^{+}$for silica nanoparticles and their adsorption at the ITIES showed that $\mathrm{MB}^{+}$can be accumulated at the interface. As a result, the transfer of $\mathrm{MB}+$ in the presence of silica nanoparticle was monitored at $\mathrm{MB}^{+}$concentrations that were not detected in the absence of silica nanoparticles.

\section{Acknowledgements}

The authors are grateful to the Agence Nationale pour la Recherche for the funding of the HYPERION project (grant number: ANR-14-CE14-0002-01). MC is grateful to SESAMES Doctoral school for $\mathrm{PhD}$ funding.

\section{References}

[1] R.A.W. Dryfe, Modifying the liquid/liquid interface: pores, particles and deposition., Phys. Chem. Chem. Phys. 8 (2006) 1869-1883. doi:10.1039/b518018j.

[2] S.G. Booth, R.A.W. Dryfe, Assembly of Nanoscale Objects at the Liquid/Liquid Interface, J. Phys. Chem. C. 119 (2015) 23295-23309. doi:10.1021/acs.jpcc.5b07733.

[3] L. Poltorak, A. Gamero-Quijano, G. Herzog, A. Walcarius, Decorating soft electrified interfaces: From molecular assemblies to nano-objects, Appl. Mater. Today. 9 (2017) 533-550. doi:10.1016/j.apmt.2017.10.001.

[4] M.D. Scanlon, E. Smirnov, T.J. Stockmann, P. Peljo, Gold Nanofilms at Liquid-Liquid Interfaces: An Emerging Platform for Redox Electrocatalysis, Nanoplasmonic Sensors, and Electrovariable Optics, Chem. Rev. (2018). doi:10.1021/acs.chemrev.7b00595.

[5] H. Duan, D. Wang, D.G. Kurth, H. Möhwald, Directing self-assembly of nanoparticles at water/oil interfaces, Angew. Chem. Int. Ed. 43 (2004) 5639-5642.

doi:10.1002/anie.200460920. 
[6] W.H. Binder, Supramolecular assembly of nanoparticles at liquid-liquid interfaces., Angew. Chem. Int. Ed. 44 (2005) 5172-5175. doi:10.1002/anie.200501220.

[7] A. Böker, J. He, T. Emrick, T.P. Russell, Self-assembly of nanoparticles at interfaces, Soft Matter. 3 (2007) 1231-1238. doi:10.1039/b706609k.

[8] L. Hu, M. Chen, X. Fang, L. Wu, Oil-water interfacial self-assembly: a novel strategy for nanofilm and nanodevice fabrication, Chem. Soc. Rev. 41 (2012) 1350-1362. doi:10.1039/C1CS15189D.

[9] B. Su, J.-P. Abid, D.J. Fermín, H.H. Girault, H. Hoffmannová, P. Krtil, et al., Reversible Voltage-Induced Assembly of Au Nanoparticles at Liquid|Liquid Interfaces, J. Am. Chem. Soc. 126 (2004) 915-919. doi:10.1021/ja0386187.

[10] H. Jensen, D.J. Fermín, J.E. Moser, H.H. Girault, Organization and Reactivity of Nanoparticles at Molecular Interfaces. Part I. Photoelectrochemical Responses Involving TiO 2 Nanoparticles Assembled at Polarizable Water|1,2-Dichloroethane Junctions, J. Phys. Chem. B. 106 (2002) 10908-10914. doi:10.1021/jp0261253.

[11] D.J. Fermín, H. Jensen, J.E. Moser, H.H. Girault, Organisation and Reactivity of Nanoparticles at Molecular Interfaces. Part II. Dye Sensitisation of TiO2 Nanoparticles Assembled at the Water|1,2-Dichloroethane Interface, ChemPhysChem. 4 (2003) 8589. doi:10.1002/cphc.200390013.

[12] S. Biswas, L.T. Drzal, A novel approach to create a highly ordered monolayer film of graphene nanosheets at the liquid-liquid interface, Nano Lett. 9 (2009) 167-172. doi:10.1021/nl802724f.

[13] M.M. Gudarzi, F. Sharif, Self assembly of graphene oxide at the liquid-liquid interface: A new route to the fabrication of graphene based composites, Soft Matter. 7 (2011) 3432-3440. doi:10.1039/c0sm01311k.

[14] X. Bian, M.D. Scanlon, S. Wang, L. Liao, Y. Tang, B. Liu, et al., Floating conductive catalytic nano-rafts at soft interfaces for hydrogen evolution, Chem. Sci. 4 (2013) 3432. doi:10.1039/c3sc51290h.

[15] P. Ge, M.D. Scanlon, P. Peljo, X. Bian, H. Vubrel, A. O’Neill, et al., Hydrogen evolution across nano-Schottky junctions at carbon supported MoS2 catalysts in biphasic liquid systems, Chem. Commun. 48 (2012) 6484. doi:10.1039/c2cc31398g.

[16] E. Smirnov, P. Peljo, M.D. Scanlon, H.H. Girault, Interfacial Redox Catalysis on Gold Nanofilms at Soft Interfaces, ACS Nano. 9 (2015) 6565-6575. doi:10.1021/acsnano.5b02547.

[17] E. Smirnov, P. Peljo, M.D. Scanlon, H.H. Girault, Gold Nanofilm Redox Catalysis for Oxygen Reduction at Soft Interfaces, Electrochim. Acta. 197 (2016) 362-373. doi:10.1016/j.electacta.2015.10.104.

[18] M.D. Scanlon, P. Peljo, M.A. Méndez, E. Smirnov, H.H. Girault, Charging and discharging at the nanoscale: Fermi level equilibration of metallic nanoparticles, Chem. Sci. 6 (2015) 2705-2720. doi:10.1039/C5SC00461F.

[19] P. Peljo, M.D. Scanlon, A.J. Olaya, L. Rivier, E. Smirnov, H.H. Girault, Redox Electrocatalysis of Floating Nanoparticles: Determining Electrocatalytic Properties without the Influence of Solid Supports, J. Phys. Chem. Lett. 8 (2017) 3564-3575. doi:10.1021/acs.jpclett.7b00685. 
[20] P.-P. Fang, S. Chen, H. Deng, M.D. Scanlon, F. Gumy, H.J. Lee, et al., Conductive gold nanoparticle mirrors at liquid/liquid interfaces., ACS Nano. 7 (2013) 9241-8. doi:10.1021/nn403879g.

[21] B.P. Binks, C.P. Whitby, Silica Particle-Stabilized Emulsions of Silicone Oil and Water: Aspects of Emulsification, Langmuir. 20 (2004) 1130-1137. doi:10.1021/la0303557.

[22] Z. Niu, J. He, T.P. Russell, Q. Wang, Synthesis of Nano/Microstructures at Fluid Interfaces, Angew. Chemie Int. Ed. 49 (2010) 10052-10066. doi:10.1002/anie.201001623.

[23] D.C.E. Calzolari, D. Pontoni, M. Deutsch, H. Reichert, J. Daillant, Nanoscale structure of surfactant-induced nanoparticle monolayers at the oil-water interface, Soft Matter. 8 (2012) 11478. doi:10.1039/c2sm26520f.

[24] M.S. Manga, T.N. Hunter, O.J. Cayre, D.W. York, M.D. Reichert, S.L. Anna, et al., Measurements of Submicron Particle Adsorption and Particle Film Elasticity at OilWater Interfaces, Langmuir. (2016) acs.langmuir.5b04586. doi:10.1021/acs.langmuir.5b04586.

[25] X. Hua, M.A. Bevan, J. Frechette, Competitive Adsorption between Nanoparticles and Surface Active Ions for the Oil-Water Interface, Langmuir. (2018) acs.langmuir.8b00053. doi:10.1021/acs.langmuir.8b00053.

[26] J.X. He, M.Y. Cui, Y.Y. Zheng, W.H. Tang, B.Y. Chen, K. Tsukamoto, et al., Selfassembly of modified silica nanospheres at the liquid/liquid interface, Mater. Lett. 64 (2010) 463-465. doi:10.1016/j.matlet.2009.11.048.

[27] W. Fan, M. Chen, S. Yang, L. Wu, Centrifugation-assisted Assembly of Colloidal Silica into Crack-Free and Transferrable Films with Tunable Crystalline Structures, Sci. Rep. 5 (2015) 1-10. doi:10.1038/srep12100.

[28] S. Dai, M.C. Burleigh, Y.H. Ju, H.J. Gao, J.S. Lin, S.J. Pennycook, et al., Hierarchically Imprinted Sorbents for the Separation of Metal Ions, J. Am. Chem. Soc. 122 (2000) 992-993. doi:10.1021/ja993168x.

[29] G. Herzog, Recent developments in electrochemistry at the interface between two immiscible electrolyte solutions for ion sensing, Analyst. 140 (2015) 3888-3896. doi:10.1039/C5AN00601E.

[30] F. Yan, X. Lin, B. Su, Vertically ordered silica mesochannel films: electrochemistry and analytical applications, Analyst. 141 (2016) 3482-3495. doi:10.1039/C6AN00146G.

[31] L. Poltorak, G. Herzog, A. Walcarius, In-situ formation of mesoporous silica films controlled by ion transfer voltammetry at the polarized liquid-liquid interface, Electrochem. Commun. 37 (2013) 76-79. doi:10.1016/j.elecom.2013.10.018.

[32] L. Poltorak, G. Herzog, A. Walcarius, Electrochemically Assisted Generation of Silica Deposits Using a Surfactant Template at Liquid/Liquid Microinterfaces, Langmuir. 30 (2014) 11453-11463. doi:10.1021/la501938g.

[33] L. Poltorak, K. Morakchi, G. Herzog, A. Walcarius, Electrochemical characterization of liquid-liquid micro-interfaces modified with mesoporous silica, Electrochim. Acta. 179 (2015) 9-15. doi:10.1016/j.electacta.2015.01.129. 
[34] Y. Liu, A. Holzinger, P. Knittel, L. Poltorak, A. Gamero-Quijano, W.D.A. Rickard, et al., Visualization of Diffusion within Nanoarrays, Anal. Chem. 88 (2016) 6689-6695. doi:10.1021/acs.analchem.6b00513.

[35] A. Holzinger, G. Neusser, B.J. Austen, A. Gamero-Quijano, G. Herzog, D.W.M. Arrigan, et al., Investigation of modified Nanopore Arrays by FIB/SEM Tomography, Faraday Discuss. (2018) doi: 10.1039/C8FD00019K. doi:10.1039/C8FD00019K.

[36] Z. Teng, G. Zheng, Y. Dou, W. Li, C.-Y.Y. Mou, X. Zhang, et al., Highly Ordered Mesoporous Silica Films with Perpendicular Mesochannels by a Simple StöberSolution Growth Approach, Angew. Chemie Int. Ed. 51 (2012) 2173-2177. doi:10.1002/anie.201108748.

[37] W. Li, L. Ding, Q. Wang, B. Su, Differential pulse voltammetry detection of dopamine and ascorbic acid by permselective silica mesochannels vertically attached to the electrode surface., Analyst. 139 (2014) 3926-31. doi:10.1039/c4an00605d.

[38] X. Huang, L. Xie, X. Lin, B. Su, Permselective Ion Transport Across the Nanoscopic Liquid/Liquid Interface Array, Anal. Chem. 88 (2016) 6563-6569. doi:10.1021/acs.analchem.6b01383.

[39] X. Huang, L. Xie, X. Lin, B. Su, Detection of Metoprolol in Human Biofluids and Pharmaceuticals via Ion-Transfer Voltammetry at the Nanoscopic Liquid/Liquid Interface Array, Anal. Chem. 89 (2017) 945-951. doi:10.1021/acs.analchem.6b04099.

[40] L. Xie, X. Huang, B. Su, Portable Sensor for the Detection of Choline and Its Derivatives Based on Silica Isoporous Membrane and Gellified Nanointerfaces, ACS Sensors. 2 (2017) 803-809. doi:10.1021/acssensors.7b00166.

[41] M.H. Abraham, A.F. Danil de Namor, Solubility of electrolytes in 1,2-dichloroethane and 1,1-dichloroethane, and derived free energies of transfer, J. Chem. Soc. Faraday Trans. 1. 72 (1976) 955-962.

[42] G. Herzog, W. Moujahid, J. Strutwolf, D.W.M. Arrigan, Interactions of proteins with small ionised molecules: electrochemical adsorption and facilitated ion transfer voltammetry of haemoglobin at the liquid|liquid interface, Analyst. 134 (2009) 1608. doi:10.1039/b905441n.

[43] Y. Xu, M.P. Konrad, W.W.Y. Lee, Z. Ye, S.E.J. Bell, A Method for Promoting Assembly of Metallic and Nonmetallic Nanoparticles into Interfacial Monolayer Films, Nano Lett. 16 (2016) 5255-5260. doi:10.1021/acs.nanolett.6b02418.

[44] M. Kosmulski, Positive Electrokinetic Charge of Silica in the Presence of Chlorides, J. Colloid Interface Sci. 208 (1998) 543-545. doi:10.1006/JCIS.1998.5859.

[45] P.S. Toth, R.A.W. Dryfe, Novel organic solvents for electrochemistry at the liquid/liquid interface, Analyst. 140 (2015) 1947-1954. doi:10.1039/C4AN02250E.

[46] C. Párkányi, C. Boniface, J.. Aaron, M. Maafi, A quantitative study of the effect of solvent on the electronic absorption and fluorescence spectra of substituted phenothiazines: evaluation of their ground and excited singlet-state dipole moments, Spectrochim. Acta Part A Mol. Spectrosc. 49 (1993) 1715-1725. doi:10.1016/05848539(93)80239-7.

[47] D. Heger, J. Jirkovský, P. Klán, Aggregation of methylene blue in frozen aqueous solutions studied by absorption spectroscopy, J. Phys. Chem. A. 109 (2005) 6702- 
6709. doi:10.1021/jp050439j.

[48] X. Yu, L. Huang, Y. Wei, J. Zhang, Z. Zhao, W. Dai, et al., Controllable preparation, characterization and performance of $\mathrm{Cu} 2 \mathrm{O}$ thin film and photocatalytic degradation of methylene blue using response surface methodology, Mater. Res. Bull. 65 (2015) 410 417. doi:10.1016/j.materresbull.2015.01.009.

[49] E. Morgounova, Q. Shao, B.J. Hackel, D.D. Thomas, S. Ashkenazi, Photoacoustic lifetime contrast between methylene blue monomers and self-quenched dimers as a model for dual-labeled activatable probes, J. Biomed. Opt. 18 (2013) 056004. doi:10.1117/1.JBO.18.5.056004.

[50] D.B. Tada, L.L.R. Vono, E.L. Duarte, R. Itri, P.K. Kiyohara, M.S. Baptista, et al., Methylene Blue-Containing Silica-Coated Magnetic Particles: A Potential Magnetic Carrier for Photodynamic Therapy, Langmuir. 23 (2007) 8194-8199. doi:10.1021/la700883y.

[51] V. Russo, D. Masiello, M. Trifuoggi, M. Di Serio, R. Tesser, Design of an adsorption column for methylene blue abatement over silica: From batch to continuous modeling, Chem. Eng. J. 302 (2016) 287-295. doi:10.1016/j.cej.2016.05.020.

[52] Y. He, L. Ding, B. Su, Vertically ordered silica mesochannels as preconcentration materials for the electrochemical detection of methylene blue, Sci. China Chem. (2015). doi:10.1007/s11426-015-5365-2.

[53] H. Nagatani, T. Sakamoto, T. Torikai, T. Sagara, Encapsulation of Anilinonaphthalenesulfonates in Carboxylate-Terminated PAMAM Dendrimer at the Polarized Water|1,2-Dichloroethane Interface, Langmuir. 26 (2010) 17686-17694. doi:10.1021/la1032477.

[54] H. Sakae, H. Nagatani, K. Morita, H. Imura, Spectroelectrochemical characterization of dendrimer-porphyrin associates at polarized liquid|liquid interfaces., Langmuir. 30 (2014) 937-45. doi:10.1021/la404079m.

[55] T. Osakai, T. Yoshimura, D. Kaneko, H. Nagatani, S.H. Son, Y. Yamagishi, et al., Potential-modulated fluorescence spectroscopy of zwitterionic and dicationic membrane-potential-sensitive dyes at the 1,2-dichloroethane/water interface, Anal. Bioanal. Chem. 404 (2012) 785-792. doi:10.1007/s00216-012-6199-9.

[56] J.S. da Silva, H.C. Junqueira, T.L. Ferreira, Effect of $\mathrm{pH}$ and dye concentration on the n-octanol/water distribution ratio of phenothiazine dyes: a microelectrode voltammetry study, Electrochim. Acta. 144 (2014) 154-160. doi:10.1016/j.electacta.2014.08.094. 